\title{
Merger, Acquisition and Employees' Work Attitude after Bank Reform in Nigeria
}

\author{
John Dokotria ${ }^{*}$, Dung Ezekiel Jidongb, Victor Dung Pamc, \\ a (NCE, B.Sc., M.Sc., Ph.D.), Psychology Department, University of Jos. Jos Nigeria. Phone: +2348037262742 \\ bSchool of Psychology, University of East London, UK. E-mail:dung.jidong@gmail.com, \\ Phone: +2348036342955 \\ c Department of Psychology, University of Jos, NigeriaE-mail:vic4pam@gmail.com, Phone: +2348035753513 \\ *Corresponding author's email address:jdokotrilang@yahoo.com
}

\section{A R T I C LE I N F O}

Received: 02-06-2016

Accepted: 04-07-2016

Available online: 29-09-2016

\section{Keywords:}

Acquisition;

Merger;

Reform in Nigeria;

Work Attitude.

JEL Classification:

G34, J23, L23

\section{A B S T R A C T}

The increasing wave of merger and acquisition in organizations are global experiences and especially in Nigeria since significant banking reforms of 2005, which has created challenges over the years to policy makers, management practitioners, organizational researchers and consultants over the failure of the survival of $75 \%$ of most of these corporate marriages at post-merger and acquisition. This study examined the varying effects of the feelings and beliefs of retained employees on conditions of merger and acquisition consequent upon work attitude. Using organizational commitment scale (OCS) and job satisfaction scale (JSS), 280 participants with 140 each on conditions of merger and acquisition were assessed. There were 151 males and 129 females of the age ranged between 25 to 51 years, represented across the banks and selected by means of purposive sampling. A hypothesis was examined at .05 significant levels using the t-test. Result of the prediction that significant reactions emanating from reforms were experienced more in acquired than merged banks on employees' measures of work attitude at post merger and acquisition. The result of the study proposes that merger and acquisition are technically distinct and vary on their effects across the varying conditions of merger and acquisition. It is further deduced that changes that emanated at post integration producedseparate qualities of marriage which caused the differential resultant effects across merged and acquired banks. The implication reveals that though negative reactions were experienced across merged and acquired banks, acquired banks had the worst of experiences thereby entailing more positive work attitude in merged than acquired banks. This statement establishes the empirical distinctiveness of merger and acquisition.

(C) 2016 The Authors. This is an open access article under the terms of the Creative Commons Attribution License 4.0, which allows use, distribution and reproduction in any medium, provided the original work is properly cited.

\subsection{Introduction}

The Nigerian banking system in its recent history has experienced tremendous regulatory policies between 2005 and 2015, ranging from the adoption of 25 billion naira capitalization to Treasury Single Account (TSA). These regulatorypolicies had their reasons, however, had their concomitant discomfort associated with issues that implicated governments, ministries, parastatals, and agencies by the surrendering of their accounts with 
commercial banks for single treasury disposition with the Central Bank of Nigeria in the 2015 policy, to the 25 billion naira capital base of 2005 .

The experience of 2005 on 25 billion naira capitalization led to series of mergers and acquisitions from such reforms that begot changes in the formation of new emerging banks from such organizational marriages. Though the organizational marriages were inevitable and undertaken for good reasons, many researchers believed that about $75 \%$ of them failed at post-merger or acquisition because of work environmental changes that accompanied new conditions and work procedures. Many researchers (e.g.,Ezurike, 2004; Muchinsky, 2003) believe that such changes could be consequential on work outcomes from employees' reactions and in the long run generate negative work attitude at post-merger and acquisition amongst surviving (i.e., retained) employees.

Many reasons were put forward to account for the sudden mergers and acquisitions in the banking industries in Nigeria from 2005. The strongest reason being the policy statement of July 06, 2004 by the governor Central Bank of Nigeria for a 25 billion naira capital base by commercial banks in order to reposition and consolidate the banks to further Nigerian's economic development (Babalola, 2008: Musa, 2006). From the scientific perspective, it is rather held against time as the strongest reason for such events to happen, hence, reducing the banks in the first instance from 89 to a manageable 25 in order to increase their competitiveness.

According to Royal Heritage (2007), several entities emerged through merger and acquisition as a process to consolidate the banking sector. Among some of the banks that were involved in acquisition as at 2005 includes; Union Bank, Oceanic Bank, Spring Bank, Afri Bank and Diamond Bank. Some others whose transactions were merged, includes; Intercontinental Group, United Bank for Africa(UBA), Platinum Bank, Sky Bank, First Inland Bank( later FIN Bank and now FCMB) and Unity Bank(Royal Heritage 2007).

These organizational marriages are a process. As it stands, Oceanic Bank is nonexistent as it is subsumed by Eco Bank. Similarly, Spring Bank, Intercontinental Bank, Platinum Bank among others, are nonexistent as they were either merged or acquired to make parties increase their capital base. This process of continues merger and acquisition pre-supposes the dynamism within the banking sector and the emergent of new entities that were possibly different in their quality of formations, as well, advance differential effects on generated reactions among employees on conditions of merger and acquisition. Presumably the reactions by extension may cause variation on employees' work attitudes across merged and acquired banks because of the varying degrees of change that resulted from the type of corporate marriages.

Some of these work attitudes according to Muchinsky (2003) are very important attitudes which employees hold, because they determine performance. They include; job satisfaction, organizational commitment and or loyalty. The positive or negative aspects of employees' work attitude are bound to fluctuate especially under changing environmental conditions where reforms in these banks may have led to mergers and acquisitions. Regardless of their importance, Adeleye (2008)and Nwoye (1997)have observed the less attention organizations give on loyalty and commitment considering the fact that job attitude related issues have direct bearing on beliefs and feelings of employees.

Emerging organizations from corporate marriages(i.e., mergers and acquisitions) are serious changes which can create differential effects on the merged or acquired organizations and farther affect divergent organizational attitudes. The aforesaid is what has notably generated a lot of concern amongst policy makers, organizational consultants, practitioners and scientific researchers by their acknowledgement of the consequences which they hold on the performances and effectiveness of the merged and acquired banks. For example, aversive consequences experienced after merger and acquisition may cause frustration, distrust, resentment, reaction and feelings of anger and injustice as product of perceptions of existing employees after reforms. Beliefs, feelings and emotional episodes are indeed all products of our perceptions and Robinson (1996) has reemphasized the repercussion these consequences have on employees' attitudes.

From this background, this study has the focus on the consequences of change from bank reforms and the probable varying repercussions they have on feelings and beliefs of retained employees at post merger and acquisition. It is assumed that feelings and beliefs held towards the attitude object (e.g., differential promotion or demotion) may influence varying degree of work attitudes across conditions of merger and acquisition and by extension individual and organizational work outcomes based on quality of the organizational marriage. The study therefore identifies merger and acquisition as product of reforms and the independent variable or the presumed cause, while work attitude is the dependent variable or presumed effect. 


\subsection{Literature Review}

\subsection{Merger and Acquisition}

Available literatures have shown many relevant studies to have been conducted on merger and acquisition, in particular, "the banking sector reforms and the Nigerian economy in relation to performance, pitfalls, and future policy options" (Balogun 2008). Empirical studies of banking sector reforms have shown that market reforms, though characterized by improved incentives, does not however, translate to increased credit purvey to the real sector. Among the pitfalls of reforms identified by the study are faulty premise and wrong sequencing of reforms, and a host of conflicts emanating from adopted theoretical models for reforms and also, frequent reversals and, or non-sustainability of reforms. The implication of this study is the adoption of deliberate policy and insurance of convergence of domestic and international rates of return on financial markets of investments.

Other studies, especially one byEmeni, and Okafor (2008) on the "effects of bank mergers and acquisitions on small business lending in Nigeria", have identified the reform to have effects on the lending of small businesses. In this study, Emeni and Okafor (2008), collected data by cross sectional survey and analysed by ordinary least square method, shows that, size, financial characteristics and deposits of non-merged banks are positively related to small business lending, while for merged banks, the reverse is the case. Evidence from this study emphasizes the static and dynamic effects of mergers and acquisitions on small business lending. This study however, suggests the outcome of this finding as a challenge to policy makers in Nigeria especially with the current government policy on industrialization.

According to Agbo (2006), mergers in non-financial sectors involving UNIPETROL, now OandoPlc, has empirical evidence from opinion sought and critical analysis of the financial statement shows that the process of merging has significantly affected the profitability of Oando Plc. Suggestions on expanding Oando's marketing outlets, close monitoring of their accounting system and prudent management in its operations, were recommended.

In a study to identify human resource problems of mergers and acquisitions, Marks and Mirvis (2000) in their eight-year study, found that corporate executives generally failed to integrate human resources aspects into the merger and acquisition process as a result of lack of familiarity with the appropriate methods of managing the change in their organizations. Also they do not realize that the merger and acquisition might have a significant negative effect on their employees. Instead, attention is more given to financial and legal concerns at the premerger or acquisition stage. Similarly,Bohl (1999) surveyed 109 companies with active merger and acquisition program and found that the human resource function was not considered in the pre-merger and acquisition planning in about two-thirds of companies reporting post-event problems, while the same was true in only about half of those reporting no problems. Another difficult trend experienced by managers is that the often miss the due diligence process of retaining the chief human assets acquired in a merger or acquisition. In a study by Forum Corporation utilizing more than 300 executives worldwide shows that managers face the challenge of talent retention that leads to successful merger and acquisition (Paton, 2007).

Other researchers carried out a study to examine the relationship between acquisition and top management's turnover rates in five years after acquisition;Walsh (1988) in a study, involving 444 companies, utilizing control group analysis found that $25 \%$ of managers do leave in the first year, $46 \%$ by year three, and $59 \%$ by year five. Similar studies involving mergers (e.g. Hayes, 1979) has found that only $42 \%$ of top management do stay with the merged entity for five years after the merger. The outcome of the studies on turnover after merger or acquisition, presupposes that the turnover rates could be high.

On yet another study on the psychological effects of mergers and acquisitions on selected banks in Nigeria, Olatunji and Uwalomwa (2009), identified the problem where many bank employees experience numerous psychological effects of merger and acquisition. That acquisition is often seen to have negative impacts on employees' behavior, resulting in counterproductive practices; absenteeism, low morale and job dissatisfaction. It also identified the problem of integration at the different stages of merger and acquisition. Their paper observed that various factors relate to pre and post mergers and acquisition stages (e.g. communication as the most vital) whose attention may effectively reduce the negative psychological and behavioral consequences and in turn reduce anxiety, uncertainty, confusion, rumour activity and labour turnover.

Kolo's (2007) study, examined the effect of bank consolidation on wealth returns of acquiring banks shareholders during, before and after the period of announcement. The study used the ordinary least square model to estimate weekly Average Returns and Cumulative Abnormal Returns of 22 acquisitions around the announcement date from January through December, 2006 to test the effect of acquisition size with a random sample of ten (10) most capitalized banks and twelve (12) medium to small acquisitions. Medium-to-small 
acquisitions (merger of equal), were found to be statistically insignificant on neutral and positive abnormal returns for acquiring banks during the announcement period. Large acquisitions in market mergers had significant positive abnormal returns for all acquiring banks that were documented around the announcement date. The most notable finding was the acquisitions of FBN and ZIB which were significantly larger than the abnormal returns associated with medium-to-small acquisitions. The study by Kolo (2007) was more centred on the impact of Nigeria's bank consolidation on shareholders returns. It had little or nothing to do with employees or management of these banks on their consolidation exercise.

\subsection{Acquisition and Attitude}

There is an emerging body of scholarly work on issues pertaining merger and acquisition. One of such related areas is acquisition and attitude. In recent times, a number of empirical studies have been conducted on acquisition and employees' attitude. In particular, research by Newman and Krzystofiak (2011) with respect to change linked to employees' attitudes after acquisition, the researchers examined the information obtained on job characteristics, facet satisfaction, overall satisfaction and organizational commitment, among 108 bank employees before the announcement of acquisition. After the acquisition, they researchers later examined 49 employees. Using a correlation analysis and a repeated measures ANOVA, indicated significant declines in perceived job characteristics, satisfaction, and organisational commitment after the acquisition. While Cartwright and Cooper (1993) in an earlier research, utilized questionnaires on 300 sampled employees to assess the extent to which organizational commitment, job satisfaction and physical and psychological health were impacted by an acquisition. Their research found no evidence of a negative impact on overall levels of job satisfaction of employees within an acquired firm as against Buono and Bowditch (1989), who found negative employee reactions to a merger or acquisition, leading to lower levels of job security, job satisfaction and less favourable attitudes toward management.

The contradictions in the outcome of the research by Newman and Krzystofiak (2011), and that of Cartwright and Cooper (1993), could have been influenced by the variance in sample size. The environment and method of research could have also contributed in the contradiction of results. Some researchers (e.g., Ashford, 1988; Amiot, Terry, Jimmieson and Callan, 2006; Van Dick, Ullrich and Tissington, 2006) examined that attitude of employees depends on their experiences on how far they believe the situation is threatening or dangerous to themselves. Their investigation suggests the role of perception in determining the degree of negative impact of the acquisition.

Guerrero (2008) rather investigated on how employees' reaction tends to vary in the event of an acquisition and found out that it depends on the acquisition context. In a research spanning over a period of five years, utilizing employees from eighty five (85) sites belonging to three different firms, found that employees working at sites belonging to the firm taken over in a friendly acquisition, have higher organizational identification scores than those at sites belonging initially to firm absorbed in a hostile acquisition. More so, additional result show increase on insecurity scores at all sites after the acquisition period, even with employees who originally belonged to the acquiring firm. The differences on employees' attitude between friendly and hostile acquisitions indicate a variation on the two conditions and possible knowledge, applicable on varying conditions of merger and acquisition. Also that employees' attitude will differ before and after acquisition. Furthermore, Van Knippenberg, Martin, and Tyler (2006) found that merger and acquisition threaten employees' identification processes because they usually require an organizational change that calls for dis-identification with previous organizational attributes, the forming of a new identity and re-identification with the new entity. Similarly, Van Dick et al., (2006) have shown from their empirical research that rejection of identity is common in mergers and acquisitions involving major changes. They studies (e.g., Guerrero, 2008) is of the position that as well as issues of attitude varies on conditions of friendly and hostile acquisitions, some others (e.g., Van Dick et al., 2006; and Van Knippenberg, 2006) hold that major changes on merger and acquisition do result to re-identification and consequently affects employees attitudes.

\subsection{Merger and Attitude}

Studies involving mergers and acquisitions on attitude and behaviour have been examined collectively by some researchers. For example, empirical evidences have shown high turnover, low morale, satisfaction, and commitment, unproductive behaviour, sabotage, and absenteeism to lead to negative employee attitudes and behaviours (Morrison and Robinson, 1997; Robinson and Rousseau, 1994), decrease in employee trust (Pritchett, 1985). In a separate study, Marmenout (2011) examined how employees make sense of a merger announcement and investigated the relationship between deal characteristics (culture clash potential, degree of integration, position in deal structure) and employee attitudes. Using a sense making mechanism proposed to test graduate students subjected to merger scenarios, employees made sense of the merger and higher 
perceived uncertainty was found to be associated with greater dysfunctional outcomes. Although perceived uncertainty mediates the effect of perceived cultural similarity on employee attitudes, the investigation found it not to be so for perceived power. The study also found that an employee's position in the deal structure strongly influences perceived power but unexpectedly, higher perceived power does not reduce uncertainty. Results still showed greater perceived power to be directly associated with lower intention to leave and greater satisfaction.

Considering that perception has a resultant effect on most of our attitudes and behaviours, the perceived role of uncertainty in the study by Marmenout (2011) mediates to affect employees' attitude in merger situations. Although the types of attitudes or dysfunctional outcomes are not specified, Morrison and Robinson (1997) had advanced some of these attitudes. Davy, Kinicki, Kilroy, and Scheck (1988), rather found that feelings of job insecurity among employees involved in mergers increased significantly, while organizational commitment as an attitude variable, decreased significantly. Buono and Bowditch (1989) in a study of mergers found in one of their investigations that they lead to lower job satisfaction and less favourable attitudes toward management.

\subsection{Merger and Acquisition as Forms of Organisational Change}

The frequency or depths of change in organizations have increased tremendously in every generation since industrial revolution (Grey, 2003). Though driven by new technology, economy, globalization and banking reforms, is a boundary shift to fit the environment.

Mergers and acquisitions are contingent on the request of the environment in order to make them consolidate and increased their size. Mintzberg (1993), states that organizations evolve to reach a certain form and shape through the structure or the formal components of an organisation. The aforesaid would mean that every organization will continually seek to find a structure that is congruent to its environment to be adaptive for it to survive.

According to Mintzberg (1993), the structure of an organization is "the sum total of the ways in which its labour is divided into distinct tasks and then its coordination is achieved among these tasks". This would imply that organizations that apply the principle of job rotation or enlargement are continually involved in change. Since employees are those that assume roles within organizations, they feel the brunt of change caused by the continuing evolution of an organization's structure.

It follows therefore that with structures as adaptive mechanism of organizations to their environments, they could cause change. According to Muchinsky (2003), organizational structures could be changed by reorganizing. This explains how employee relationships may change when organizations expand because of greater opportunism to sell their products and services, will therefore require the organisation to reconfigure them to better adapt to their environments. Similarly, in mergers and acquisitions, it is believed that one of the major reasons for such marriages is to expand and have a heavy sized version of the original organizations. This presupposes that applying the principle of reorganizing will require structural change by reconfiguration.

Another form of reorganizing is downsizing (Muchinsky, 2003). This is sometimes applied as a strategy in situations of merger or acquisition where too many employees have been realized from results of such marriages. In order to control for the burden associated with huge cost of personnel, organisations are right sized by downsizing. This process according to Mintzberg (1993), amounts to change since the structure of the organization in terms of re-assigning task has to happen. Similarly, Adeyemi (2006) observes that merging or acquiring entities should consider the change management effort by coming up with a new structure of the married organizations. Reasons being that it is a key component of achieving good performance, especially at the bottom line.

According to Garrow (2008), the psychological contract as an aspect of merger or acquisition is a human variable in which the human resource is vital in maintaining or rebuilding the psychological contract against any organizational marriage or other forms of major change. This statement implies that change in organizations is not monolithic to its structures in situations of merger and acquisition, but also a scale of change on the psychological contract.

Cultures are dynamic and organizational cultures may change when corporate marriages take place. Integrating the cultures of two or more organizations that have undergone merger or even acquisition by integrating their employees, is often successful when cultures of the marrying organizations do not conflict or a new culture is formed that accommodates the merging or acquiring organizations. 
According to Beer (1980), the natural evolution of organizations is accompanied by changes in culture. It is on the basis of this, that the importance of viewing organizations from a cultural perspective cannot be overemphasized, considering the holistic perspective in which the concept of culture provides. Therefore in every organizational change, the cultures of the merging or acquiring organizations as sources of their own identity are affected. It is from this perspective that integrating cultures on the need to maintain effective working relationship amongst employees of merged or acquired banks and in the overall, employees and the organization is necessary.

There are different approaches to organizational change management used by theorists and management practitioners. Tushman, Newman and Romanelli (1986), considered the differentiation between "Convergent" and "Frame-breaking" change. Some others distinguished the organizational change management between "rational" and "action" approaches (Brewer, 1995); typology of three approaches base on power used to achieve change (Schermerhorn, 1989); and or, rational approach that describes sequential stages or phases of organisational change or linear models (Lippitt, Watson and Westley, 1958; Greiner, 1987; Kilmann, 1989).

Even thoughchange in organizations is determined by different factors, in this study, the focus is on restructured banks where activities, task, roles, assignments, and violation of the psychological contract are of concern to employees of the emerging banksafter corporate marriage. The inclusion of factors like; downsizing and culture in this literature is to further our knowledge on change as responses to policies pronounced from the environment. In short,downsizing and culture are not the core areas of change in this study.

The critique on literature of past studies on reforms has clearly suggested the alternate use of merger and acquisition to mean the same entity. Equally so in the past, some researchers only assume merger and acquisition as distinct creations thereby furthering that common sense approach to their formations as similar entities. This study is probably the only one that has empirically established the technical distinctiveness between merger and acquisition, and taken them in a single study to examine their effects on work attitudes of retained employees at post integration. From the concepts used in this study, it explains the nomothetic approach with which the research undertook, starting from a theory to results that could either support or challenge the theory. The framework of the theory (tricomponent model of attitude) has identified an attitude object of change (e.g., banking reforms) or job outcome (e.g., job loss), to trigger feelings of positive or negative assessment of our emotional experiences related to the attitude object. The belief or the cognitive component of attitude provides the connection between attitudes and our perceptions. For example, when survivors (i.e., retained employees) of banking reforms don't value the action of workers been terminated, may see this action as a breach of the psychological contract, against the perceived wrong doing by management (the attitude object). Such beliefs develop over time through direct experiences and from what co-workers tell other workers.

Attitudes develop from two sources; 1) our emotional experiences and 2) Our perception process. The third attitude component is behavioral intention. This refers to how individuals intend to behave toward something. For example, if a worker says, "I would resist a demotion", or "There is partiality on our treatment since we joined this organization". The three components are not separate; they interact among themselves and couldmanifest in a variety of forms. The approach to this study is used in a developing economy in the form of re-examining work attitudes in the Nigerian environment where such experiences of reforms are heavily experienced for the first time and especially the banking sector.

Having reviewed thus far, it is hypothesized that employees' reactions on measures of work attitude would be more experienced in acquired than merged banks by surviving employees after bank reforms. Explicitly, the prediction holds that even though employee reactions abound after merger and acquisition, feelings and beliefs held by employees of acquired banks may be more on the negative than merged banks.

\subsection{Method}

\subsection{Design}

The study used an independent group design with comparable groups on conditions of merger and acquisition. The independent variables are merger and acquisition whereas the dependent variable is work attitude (i.e, organizational commitment and job satisfaction). Purposive sampling technique was used to assign participants. This approach was found more befitting because only bank workers that experienced merger and acquisition especially employees that survived job loss in banks that were involved in mergers and acquisitions were considered.

\subsection{Participants}


A pilot study was ran which utilized one hundred and twenty (120) workers of merged and acquired banks across different ranks that included managers, banking officers, office administrators, pay tellers, team leaders, management executives and bank trainers. Sixty seven (67) of the participants were from merged banks (11 from UBA, 11 from First City Monument Bank(FCMB), 11 from Unity Bank, 14 from Fin Bank (now FCMB), 7 from Wema and 13 from Skye Bank). On the other hand, fifty three (53) were drawn from acquired banks. (i.e, 20 from Diamond Bank, 4 from Access Bank, 11 from Eco Bank, 10 from Fidelity and 8 from Spring Bank). The pilot study of the 120 participants of large $(25-53)$ years, were utilized to validated instruments on job satisfaction and organizational commitment, as measures of work attitude.

The main study utilized two hundred and eighty (280) participants with 140 each from merged and acquired banks. One hundred and fifty one (151) were males and one hundred and twenty nine (129) were females. Their age ranged between $25-51$ years.

The sample size of 280 participants was arrived at using the rule of the thumb that specifies 5 - 10 participants for every item in the scale (Cohen and Swerdlik, 2002). The utilization of 280 participants therefore falls within specifics.

\subsection{Instrument}

Organizational commitment scale (OCS) and Job satisfaction scale JSS) were used to gauge workers' attitude after merger and acquisition. The two scales were validated to get their local psychometric properties and for use in Nigeria.

The organizational commitment scale validated was originally developed by Meyer, Allen and Smith (1993). It was later modified and shortened to a 10 -item scale by Hicks (2007) to assess the three types of commitment (affective, continuance and normative) with an estimated Cronbach alpha of .85. They researchers validated the commitment scale by Hicks (2007) and found all the ten (10) items to meet a clean factor structure with factor loadings ranging from .412 to .690. The ten items comprised; 3 items on affective, 3 on continuance and 4 on normative, all used to measure the overall commitment of workers as an aspect of attitude after reforms (i.e, merger and acquisition).

The validated scale on commitment of workers after reforms have seven response categories of the Likert type ranging from strongly agree to strongly disagree. Responses on the ten items were scored by assigning the following values: Strongly Agree $=7$, Agree $=6$, Somewhat Agree $=5$, Neutral $=4$, somewhat disagree $=3$, Disagree $=2$, Strongly Disagree $=1$. Items 1 and 2 of the ten items on the OCS were reversed scored. The local psychometric properties of the scale were examined to have a Cronbach alpha of .75 with a construct validity of .77 .

Table 1: Confirmatory Factor Analysis on Measures of Organisational Commitment Scale (OCS)

No Item $\quad$ Factor Loading

1. I do not feel a strong sense of belonging to my bank since the banking reforms took place

$.493^{* *}$

2. I do not feel part of the family at my bank since merger or acquisition took place $.508^{* *}$

3 . This bank has a great deal of personal meaning to me with the banking reforms $.412^{* *}$

4. It would be very hard for me to leave this bank right now because of the recent banking reforms

$.655^{* *}$

5. Too much of my life would be disrupted if I decided I wanted to leave my bank now with the recent banking reforms

6. I feel like I have too few options to consider leaving this bank now

7. I would feel guilty if I left my bank now

8. This bank deserves my loyalty

$.565^{* *}$

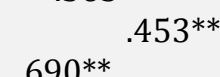

$.485^{* *}$

9. I would not leave my bank right now because I have a sense of obligation to the people in it

10. I owe a great deal to my bank since merger or acquisition took place

** Correlation is significant at the .01 and .05 levels (2- tailed).

Note: All factor loadings are $>.35$ and meet clean factor structure (Konovsky and Organ, 1996).

The factor structure of the OCS was examined and the items' confirmatory factor analyses are significant. The factor loadings ranged from .412 to .690 , and were all significant at .01 and .05 levels (2-tailed). 
The Job Satisfaction Scale (JSS) was similarly used as a component-measure of bank employees' attitude after merger and acquisition. The Job Satisfaction Scale also called the Minnesota Satisfaction Questionnaire (MSQ) short form was developed by Weiss, Dawis, England and Lofquist (1967) to measure the feelings of workers on their jobs. The scale was used extensively and examined to have a Cronbach alpha of .91 (Ben - Bakr, AlShammari and Jefri, 1994). The JSS or MSQ is a 20-item scale designed for self-report. It has a 5 point Likert format of response ranging from very dissatisfied to very satisfy.

The MSQ was re-examined by the researchers for validation and use in Nigeria to measure the job satisfaction aspect of employees' work attitude after merger and acquisition. The confirmatory factor analysis of the 20 items of the MSQ was performed with 19 out of the 20 items found to pass a clean factor structure with factor loadings between .360 to .647 all significant at the .01 and .05 levels (2-tailed).

Scoring of the items had the following values: $1=$ very dissatisfied, $2=$ dissatisfied, $3=$ neutral, $4=$ satisfied and $5=$ very satisfied. The local psychometric properties were obtained through pilot study with a Cronbach alpha of .83 and construct validity of .85

Table 2: Confirmatory factor analysis on job satisfaction scale

\begin{tabular}{|c|c|}
\hline No $\quad$ Item & Factor Loading \\
\hline \multicolumn{2}{|c|}{ On my present job since my bank merged or was acquired, this is how I feel about... } \\
\hline 1. Being able to keep busy all the time & $.518^{* *}$ \\
\hline 2. The chance to work alone on the job & $.341^{* *}$ \\
\hline 3. The chance to do different things from time to time & $.464^{* *}$ \\
\hline 4. The chance to be somebody in the community & $.524^{* *}$ \\
\hline 5. The way my boss handles subordinates & $.497^{* *}$ \\
\hline 6. The competence of my supervisor in making decisions & $.476^{* *}$ \\
\hline \multicolumn{2}{|c|}{ 7. Being able to do things that don't go against my conscience $.464^{* *}$} \\
\hline 8. The way my job provides for steady employment & $.647^{* *}$ \\
\hline 9. The chance to do things for other people & $.542^{* *}$ \\
\hline 10. The chance to tell people what to do & $.372^{* *}$ \\
\hline \multicolumn{2}{|c|}{ 11. The chance to do something that makes use of my abilities $.513^{* *}$} \\
\hline 12. The way company policies are put into practice & $.519^{* *}$ \\
\hline 13. My pay and the amount of work I do & $.424^{* *}$ \\
\hline 14. The chances for advancement on this job & $.538^{* *}$ \\
\hline 15. The freedom to use my own judgment & $.607 * *$ \\
\hline 16. The chance to try my own methods of doing the job & $.493^{* *}$ \\
\hline 17. The working conditions & $9 * *$ \\
\hline 18. The way my coworkers get along with each other & $.360^{* *}$ \\
\hline 19. The praise I get for doing a good job & $.422^{* *}$ \\
\hline 20. The feeling of accomplishment I get from the job & $.499^{* *}$ \\
\hline
\end{tabular}

\subsection{Procedure}

The pilot study on the survey instruments utilized 120 commercial bank workers from merged and acquired banks. Among the merged banks were; United Bank for Africa (UBA), First City Monument Bank (FCMB), Unity Bank, Fin Bank, Wema Bank and Skye bank. The acquisition banks included: Diamond Bank of Nigeria (DBN), Access Bank, Eco Bank, Fidelity Bank and Spring Bank. The bank workers that met the requirement of special characteristics were selected on satisfaction of the universe. That is the selection drew representation from the different banks that experienced merger or acquisition.

The pilot survey instruments were administered with the help of a Research Assistant from each of the banks. The Research Assistants were first briefed on the participants that were qualified to partake in the research and information the participants needed before responding to the questionnaires administered to them. The questionnaires for the pilot study took about 60 days to be retrieved.

On the main study, they researchers sought for the consent of the management of each selected merged or acquired bank visited. The process of briefing, using research assistants at each bank visited was carried in the main study. More so, 280 participants were rather administered questionnaires which ran through a time period of about two months to be retrieved. At retrieval of the completed questionnaires, participants were debriefed. This exercise made available aftermath information at the end of data collected. 


\subsection{Result}

\subsection{Research hypothesis}

The researchhypothesis states that, 'there would be more significant effects in acquiredthan merged banks on employees' reactions onmeasures of work attitude after bank reforms'. Two hundred and eighty (280) surviving bankers, one hundred and forty (140) each on conditions of acquisition and merger were tested. Acquired banks had a mean score of 100.36 with a standard deviation of 19.356, while merged banks scored a mean of 109.34 with a standard deviation of 18.749 . Using an independent t-test to examine the mean scores of acquired and merged banks, result showed a significant difference, $t(278)=3.939, \mathrm{p}<.05$.

This means that employees under merger revealed more positive work attitudes thanemployees under acquisition. Tables 3 and 4 presents the descriptive data and t-testanalyses respectively:

Table 3: Descriptive Statistics on Work Attitude on Merged and Acquired Banks

\begin{tabular}{lrrrrr}
\hline Type of marriage & $\mathrm{N}$ & Mean & Std. Deviation & Std. Error Mean \\
\hline Work attitude & Acquisition & 140 & 100.36 & 19.356 & 1.636 \\
Merger & 140 & 109.34 & 18.749 & 1.585 \\
\hline
\end{tabular}

Table 3 above gives the descriptive statistics of participants' work attitude on merger and acquisition. The mean and standard deviation were responses of measures of work attitude of one hundred and forty participants on each condition of merger and acquisition. These statistic which describes the data on responses of participants on hypothesis one, indicate a higher mean score of 109.34 of merged banks to 100.36 of acquired banks. Standard deviation of 18.749 of merged banks is explained as how individual scores in merged banks differ from the mean. The difference of individual scores from the mean in merged banks is not wide comparable to acquired banks with a standard deviation of 19.356 . The implication is that there was more consistency in the responses of participants in merged banks than acquired banks.

Table 4 below represent the t-statistics that compared the mean scores between merged and acquired banks on measures of work attitude. It was used to test the hypothetical statement of the study.

Table 4: Independent Samples t-test on measures of work attitude

\begin{tabular}{|c|c|c|c|c|c|c|c|c|c|c|}
\hline & & \multicolumn{2}{|c|}{$\begin{array}{l}\text { Levene's Test for } \\
\text { Equality of Variances }\end{array}$} & \multicolumn{7}{|c|}{ t-test for Equality of Means } \\
\hline & & \multirow[b]{2}{*}{$\mathrm{F}$} & \multirow[b]{2}{*}{ Sig. } & \multirow[b]{2}{*}{$t$} & \multirow[b]{2}{*}{ df } & \multirow[b]{2}{*}{ Sig. (2-tailed) } & \multirow{2}{*}{$\begin{array}{c}\text { Mean } \\
\text { Diff erence }\end{array}$} & \multirow{2}{*}{$\begin{array}{l}\text { Std. Error } \\
\text { Diff erence }\end{array}$} & \multicolumn{2}{|c|}{$\begin{array}{l}95 \% \text { Confidence } \\
\text { Interv al of the } \\
\text { Diff erence }\end{array}$} \\
\hline & & & & & & & & & Lower & Upper \\
\hline Work attitude & $\begin{array}{l}\text { Equal variances } \\
\text { assumed }\end{array}$ & .018 & .892 & -3.939 & 278 & .000 & -8.971 & 2.277 & -13.455 & -4.488 \\
\hline & $\begin{array}{l}\text { Equal variances } \\
\text { not assumed }\end{array}$ & & & -3.939 & 277.719 & .000 & -8.971 & 2.277 & -13.455 & -4.488 \\
\hline
\end{tabular}

Figure 1: Graph on work attitude on merged and acquired banks

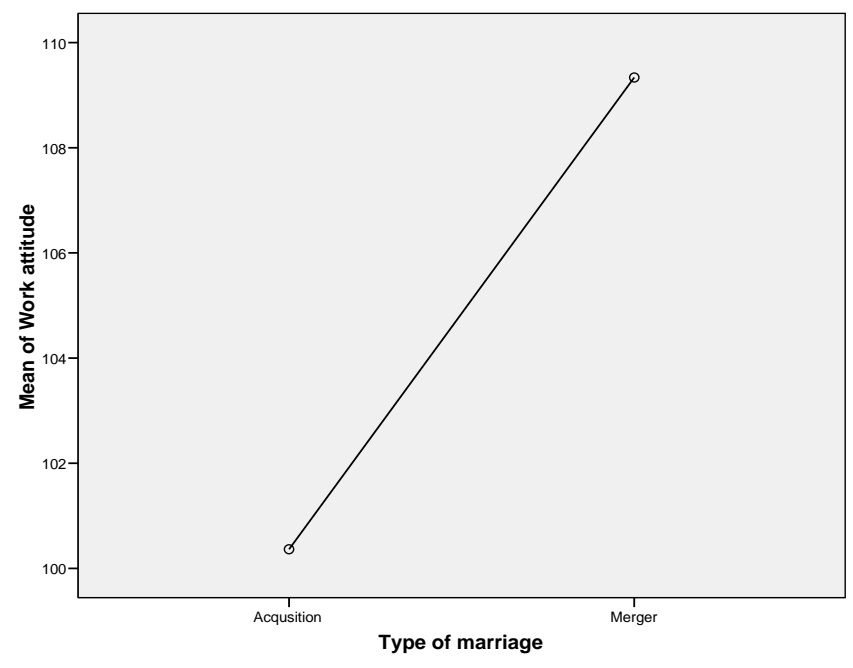


Figure 1 above shows the trend on mean difference for merger and acquisition. Lower mean scores of 100.36 for acquired banks comparable to a higher mean score of 109.34 for merged banks on measures of positive attitude, indicates more favourable work attitude responses by merged banks after reforms.

\subsection{Conclusion}

The purpose of this research was intended to determine the effects of merger and acquisition on employees' work attitude after bank reforms. The study was also interested in establishing the significant difference of work attitudes in merged and acquired banks.The researchhypothesis was tested to achieve the purpose of the study and indicated support for thestudy'sprediction as discussed thus;

Results of the study on the research hypothesis has provided some support on the prediction that there would be more significant effects in acquired than merged banks on employees'reactions onmeasures of work attitude after bank reforms. The outcome of the analysis revealed that employees in merged banks have more positive work attitude than their counterparts in acquired banks. Similar investigations (e.g, Panchal and Cartwright, 2001) have given support to this study where they considered employees reaction to emanate on the context of the merger or acquisition, hence its significant impact on employee attitudes. Some other studies (e.g, Guerrero 2008) compared changes in the reaction of three groups of employees to an acquisition and arrived at the context of the acquisition as a major determinant of work attitudes. Even though the study by Guerrero (2008)was on three groups of employees under acquisition; acquisition under friendly process, hostile process, and the parent organisation, the element of 'distinction' is implied which defines the context of the acquisition that is to vary on employees attitudes. This study however, draws such a distinction between merger and acquisition, confirming the two types of organisational marriage as distinct and therefore the possibility to exert varying degree of impact on employees' work attitude.

One striking explanation to the finding in this study is on acquisition and attitude. Newman and Krzystofiak (2011) found that differences exist on facet satisfaction, overall satisfaction and organisational commitment as aspects of the measures of attitude at pre and post acquisition. There was significant decline in perceived job characteristics, satisfaction and organisational commitment after acquisition. Though the study by Newman and Krzystofiak (2011) was not comparative, measures of attitude on condition of acquisition has revealed its contextual qualities of causing more of negative attitudes at post acquisition.

In conclusion, re-examining this study on the Nigerian environment has produced major finding that is consonant to that of other environments. There seem to be changes in attitudes that vary across conditions of merger and acquisition from feelings and beliefs of surviving (i.e., retained) employees after banking reforms. In short, feelings of violation of psychological contract from termination of other employees and other changes that may have occurred on conditions of merger and acquisition could be significant changes that may have caused varying employees' reactions. In other words, the attitude object of change (e.g., Banking reform) or job outcome (e.g., job loss), may have triggered negative assessment of our emotional experiences related to the attitude object. Hence, retained bank employees after merger or acquisition may have developed perceptions from their beliefs to have spurred them to see certain actions of the object of change as a breach or violation of their psychological contract. The varying degree of such perceptions of wrong doing over time may have caused differentials on employees' reactions under merged and acquired conditions after bank reforms.

The implication of these conclusions to researchers, policy makers, organizational consultants and human resources managers is that: first,they should have knowledge of the concept of change especially perceptions employees are likely to hold on mergers and acquisitions. Such knowledge especially at post-merger or acquisition will help them apply the most appropriate decision or strategy to stem down negative reactions that could affect work attitudes. Second,policies by bank regulating bodies must be research driven to arrive at guidelines that will accommodate restructuring and necessary human factors to help integrating organizations avoid entropy at post merger and acquisition. Third,monitoring of the processes of merger and acquisition to ensure adherence to regulatory framework is duly followed. Fifth,retained employees of corporate integration may also perceive the negative experiences of merger and acquisition as threatening to their psychological contract and therefore need different management approach after reforms.

\section{References}

Adeleye, A. (2008). Challenges of retaining best talent. Nigeria Tribune, April, 29.

Adeyemi, F. (2006).After the merger. Price Water House-Coopers Publication

http://www.pricewaterhousecoopers.com. Retrieved 21/6/2008. 
Agbo, P. O. (2006). The potentials of mergers as a tool for business competition and survival: A case study of AGIP Nigeria and UNIPETROL Plc. Unpublished dissertation Management Science, University of Jos.

Amiot, C., Terry, D., Jimmieson, N. \& Callan, V. (2006). A longitudinal investigation of coping processes during a merger implications for job satisfaction and organisational identification. Journal of Management, 32, 552574.

Ashford, S. (1988). Individual strategies for coping with stress during organisational transactions. The Journal of Applied Behavioural Science, 24, 19-36.

Babalola, R. (2008). The Nigerian Economy: A speech by Minister of State for Finance, Federal Ministry of Finance, Nigeria, may, 28

Balogun, E. D. (2008). Banking sector reforms and the Nigerian economy: Performance, pitfalls and future policy Options.http//mpra.ub.uni-muenchen.de/3804/.

Beer, M. (1980). Organisation, change and development: A Systems View. Goodyear Publishing Co, Inc. pp.32-36.

Ben-Bakr, K. A., Al-Shammari, I. S., and Jefri, O. A. (1994). Organizational commitment, satisfaction and turnover in Saudi organisations: A predictive study. Journal of Socio-Economics, 23(4), 449-456. http://dx.doi.org/10.1016/1053-5357(94)90014-0

Bohl, D. L. (1999). CBR Mini survey: Competition for Hot Talent: How Companies are responding.Compensation \& Benefits Review 31 (2): 29-36.

Brewer, A.M. (1995). Change management; Strategies for Australian organisations. Sydney: Allen and Unwin.

Buono, A.F., \& Bowditch, J.L. (1989). The human side of mergers and acquisitions: Managing collision between people, cultures, and organisations. San Francisco: Jossey-Bass.

Cartwright, S. \& Cooper, C. (1993). The psychological impact of merger and acquisition on the individual: A study of building society managers. Human Relations, 43, 327-347

Cohen, J. C., \&Swerdlik, M. E. (2002). Psychological testing and assessment: Introduction to test and measurement. Boston, U.S.A. McGraw-Hill

Davy, J. A., Kinicki, A., Kilroy, J., \& Scheck, C. (1988). After the merger: Dealing with people's uncertainty. Training and Development Journal, November, 57-61.

Emeni ,F. K., \&Okafor, C.(2008). Effects of bank mergers and acquisitions on small business lending in Nigeria.

African Journal of Business Management, 2(9) Sept, 146-156. http://WwW.academicjournals.org/AJBM

Ezurike, N. (2004). The merger and acquisition culture. In: This Day Nigeria- AAGM, Dec,19.

Garrow, V, (2008). Managing the psychological side of the contract through a merger. Report on new research from Roffey Park Institute. http://www.roffeypark.com. Retrieved, 21.06.2008.

Greiner, L.E. (1987). Patterns of organisational change. Harvard Business Review, 45 (May-June).

Grey, C. (2003). The fetish of change, Tamara: Journal of Critical Postmodern Organisation Science, 2(2), 1-19.

Guerrero, S. (2008). Changes in employees' attitudes at work following an acquisition: A comparative study by acquisition type. Human Resource Management Journal, 18(3), 216-236.

http://dx.doi.org/10.1111/j.1748-8583.2008.00068.x

Hayes, N. (2000). Doing psychological research: Gathering and analyzing data. Open University Press, Buckingham, pp. 91-107.

Hicks, M. (2007). Generation and the psychological contract: How Civil Service reform is perceived by public sector workers. Unpublished Phd thesis, Florida State University.pschcontract1mhicks 072307.pdf-Adobe Reader.

Kilmann, R.H. (1989). Managing beyond the quick fix: A completely integrated program for creating and maintaining organisational success. San Francisco: Jossey-Bass.

Kolo, A. N. (2007). Impact of Nigeria's bank consolidation on shareholder's returns. African Institute for Economic Development and Planning.http://www.unidep.org/idep/

Konovsky, M. A., \& Organ, D. W. (1996). Dispositional and contextual determinants of organizational citizenship behaviour. Journal of Organizational Behaviour, 16, 215-224.

Lippitt, R., Watson, J. \&Westly, B. (1958).The dynamics of planned change. New York: Harcourt, Brace and World.

Marks, M.L., \&Mirvis, P.H. (2000). Managing mergers, acquisitions, and alliances: creating an effective transition structure. Organisational Dynamics, 28, 35-47.

Marmenout, K. (2011). Employee sense making in mergers: How deal characteristics shape employee attitudes. Sage Journal online, marmenout@em.lyon.com, Accessed, 27.07.2011.

Meyer, J., Allen, N., and Smith, C. (1993). Commitment to organisations and occupations: Extension and test of a three-component conceptualization. Journal of Applied Psychology, 78(4), 538-551. http://dx.doi.org/10.1037/0021-9010.78.4.538

Mintzberg, H. (1993). Structure in fives: Designing effective organisations. Englewood Cliffs, NJ: Prentice Hall.

Morrison, E. W. \& Robinson, S. L. (1997). When employees feel betrayed: A model of how psychological contract violation develops. Academy of Management Review, 22, 266-256. 
Muchinsky, P.M. (2003). Psychology applied to work. An introduction to industrial and organizational psychology. Thomson Wadsworth (7th Ed), USA, 254-258.

Musa, S. (2006). The Nigerian political economy in transition. In: Ansprech. Partner. Uta.Dirksen@fes.de.

Newman, J. M., \&Krzystofiak, F. J. (2011). Changes in employee attitudes after an acquisition: A longitudinal analysis. Sage Journal online.

Nwoye, M. I. (1997). Management practices and performance determinants of public and private enterprises in Anambra, Edo and Delta States of Nigeria: A Factor analysis. In: Journal for Political Theory and Research on Globalization.

Olatunji, O.R., \&Owalomwa, U. (2009). Psychological effects of mergers and acquisitions on employees: Case study of some selected banks in Nigeria. Available online: http://www.inderscience.metapress.com/link.asp/2009/2/1.

Panchal, S. \& Cartwright, S. (2001). Group differences in post-merger stress. Journal of Managerial Psychology, 16, 424-433.http://dx.doi.org/10.1108/02683940110402398

Paton, N. (2007).Nine out of ten mergers and acquisitions fail to deliver. Available online: http://www.management-issues.com/2007/3/26/research/nine-out-of-10-mas-fail-to-deliver.asp.

Pritchett, P. (1985). After the merger: Managing the shockwaves. Pritchett and Associates, Dallas, TX.

Robinson, S. L. (1996). Trust and breach of the psychological contract. Administration Science Quarterly, 41, 574-599.http://dx.doi.org/10.2307/2393868

Robinson, S. L. \& Rousseau, D. M. (1994). Violating the psychological contract: Not the exception but the norm. Journal of Organisational Behaviour, 15 (2), 245-259.

Royal Heritage (2007). Table of recent transactions participated in by the corporate, commercial and capital market. Group. http.//www.royalheritage@yahoo.com.

Tushman, M.L., Newman, W.A., \&Romanelli, E. (1986). Convergence and upheaval: managing the unsteady pace of organisational evolution. California Management Review.(Fall)

Van Dick, R., Ullrich, J. \&Tissington, P. (2006). 'Working under a black cloud: How to sustain organizational identification after a merger'. British Journal of Manager, 17, S69-S79.

Van Knippenberg, B., Martin, L. \& Tyler, T. (2006). 'Process-orientation versus out-orientation during organizational change: The role of organisational identification'. Journal of Organisational Behavior, 27, 685-704.

Walsh, J. P. (1988). Top management turnover following mergers and acquisitions. Strategic Management Journal, 9, 171-183.

Weiss, D. J., Dawis, R. V., England, G. W., \&Lofquist, L. H. (1967). Manual for the Minnesota Satisfaction Questionnaire. Minneapolis: Industrial Relations Centre, University of Minnesota. 